\title{
Positional Vertigo and Nystagmus of Central Origin
}

\author{
P. WATSON, H.O. BARBER, J. DECK and K. TERBRUGGE
}

SUMMARY: Four cases are described illustrating the clinical features of positional vertigo and nustagmus due to posterior fossa tumors and a case of obstructive hydrocephalus. In these cases positional vertigo was the first and only. presenting s.mptom of central nervous system disease. One case of subependymoma of the fourth ventricle and one with hydrocephalus had characteristic sympioms of benign positional vertigo; each showed positional nystagmus of the benign paroxismal type.

RESUMÉ: Nous décrivons quatre cas qui illustrent les charactéristiques cliniques du vertige positionnel et du n.stagmus consécutifs à des tumeurs de la fosse postérieure et un cas d'hydrocéphalie obstructive. Chez ces patients le vertige positionnel fut le premier et le seul symptome d'une atteinte du sisteme nerveux central. Un cas de subependymome du 4 e ventricule et un d'hydrocéphalie présentaient les symptômes caractéristiques du vertige positionnel benin; tous avaient aussi un nystagmus positionnel du type paroxystique bénin.

From the Mississauga, Sunnybrook and Toronto Western Hospitals and Department of Otolaryngology, University of Toronto.

Reprint requests to Dr. C.P. Watson, 3025 Hurontario Stret, \#504, Mississauga, Ontario, Canada. $1.5 \wedge 2 \mathrm{HI}$.

\section{INTRODUCTION}

Positional vertigo is a common type of dizziness. It usually is readily recognizable and is most often benign. The purpose of this article is to draw attention to the features of sinister positional vertigo and nystagmus, and to emphasize that it may be impossible to differentiate the benign from the more serious form at the initial assessment.

\section{CASE 1}

A 20 year old woman was seen with the complaints of dizzy spells and vomiting. For the preceding, month, when she rolled over in bed or arose quickly from bed, or looked up when standing, severe vertigo and nausea would occur, lasting a minute or two or a little longer. In the two days before her admission to hospital she had severe vomiting. She denied other symptoms. For one week before admission she noted mild occipital headache, worse in the afternoon and evening and aggravated by straining at stool, but this was not volunteered.

The past history, personal history, functional enquiry were negative.

On physical examination the sole abnormality was found with head position testing as described by Barber (1973). (The patient is moved briskly from sitting to the right and left head-hanging, neck-twist positions and maintained for 15 seconds, until nystagmus declines or for 60 seconds if persistent). This manoeuvre produced horizontal jerk nystagmus with both right and left positions, without latency, and with rapid component directed towards the ear down (geotropic). The nystagmus did not fatigue and was followed by vomiting.

Because of the association of positional dizziness with vomiting and headache, and with the particular features of the positional nystagmus, hospital admission was advised with the suspicion of a posterior fossa lesion in mind.

Investigations included normal electroencephalogram (EEG), skull $x$-ray, and radionuclide brain scan. A non-enhanced
CT scan was done which showed a poorly defined midline lesion obliterating the fourth ventricle. The density of the lesion was similar to brain and the lesion was surrounded by minimal edema. The third and both lateral ventricles were at the upper limits of normal size. The enhanced CT scan (Figure I) showed non-homogeneous enhancement of a rounded lesion. It appeared to arise from the posterior wall of the fourth ventricle or the adjacent vermis.

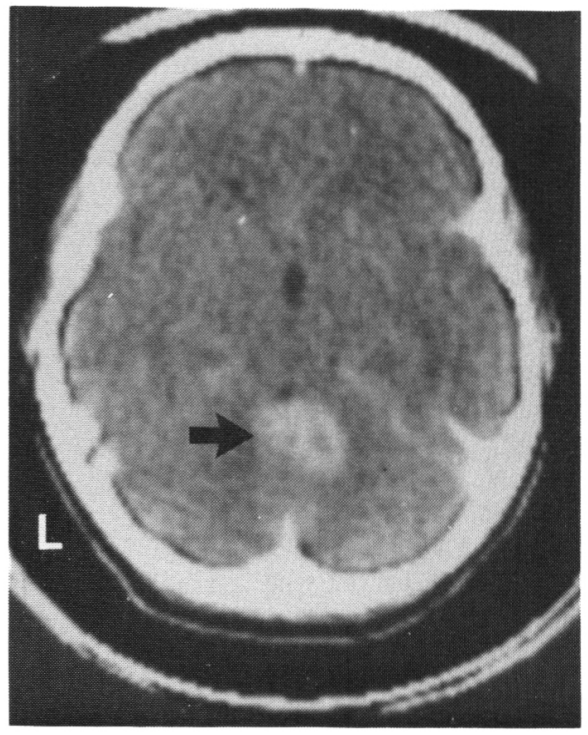

Figure I (Case I) - Enhanced CT scan shows abnormal enhancement in a nonhomogeneous fashion of a midline lesion (arrow) which obliterates the fourth ventricle.

Posterior fossa angiography showed a midline mass lesion at the level of the posterior aspect of the fourth vent ricle with displacement of the normal vasculature, but without evidence of tumor vascularity. Downward displacement of the tonsils was also noted.

At surgery the tonsils were herniated to C-2. The vermis appeared full and displaced the cerebellar hemispheres to the left and right. The tonsils were split and separated and the obex of the fourth 
ventricle was observed. No tumor was visible. On incising the inferior vermis a dark brownish-blue tumor was revealed and much of it was sucked out. The fourth ventricle was identified as far as the aqueduct of Sylvius and the tumor was peeled out of the aqueduct, lifted from the floor of the fourth ventricle and dissected out of the lateral recesses of the fourth ventricle. Substantial tumor removal was achieved and the fourth ventricle structures were in good condition. The incision was closed. Pathological examination showed a medulloblastoma of the cerebellar vermis. The patient was treated with radiation to the total neuraxis and is currently functioning normally, two years later.

\section{CASE 2}

A 28 year old woman had positional vertigo for two years. Early in the course of the illness there had been remission of the symptom for as long as two months, but it had then become persistent for many months. The symptom was usually brought on by head movement, either turning in bed, getting up from a seated position, or lying down from standing, but usually by head turning to either side, particularly with the neck extended. There was a violent feeling of vertigo which was often followed by nausea and vomiting. The vertigo usually lasted 30 to 60 seconds.

The medical, personal and family histories were negative.

On physical examination, head position testing with right head hanging produced a dramatic vertigo, after a latency of 3 to 5 seconds, lasting 5 to 10 seconds with rotatory nystagmus to the right, the 12 o'clock point of the limbus beating counterclockwise. This fatigued after two repetitions. Nystagmus or vertigo did not occur in the left head hanging position. There were no other neurological findings.

The clinical impression was that she was suffering from benign positional vertigo.

One month later she continued to have spells two or three times weekly. As time passed the vertigo became more frequent, and more severe, but continued to last a few seconds and was induced by head turning, usually in the morning upon waking or when turning quickly in bed. An audiogram and electronystagmogram (ENG) were normal.

Nine months later she still had dizziness, but nausea was continuous. She would wake and vomit each morning. The positional vertigo was unchanged.

At that time, with right head hanging after 4 to 5 seconds latency, severe vertigo and right beating rotatory nystagmus were produced which fatigued after four repe- titions of the position. There were no other physical findings.

A non-enhanced CT scan was done which showed partial obliteration of the fourth ventricle by a poorly defined midline lesion of mixed density. The lesion was surrounded by minimal edema. There was moderate enlargement of the third and both lateral ventricles. The enhanced $\mathrm{CT}$ scan showed non-homogeneous enhancement of a rounded lesion apparently located within the fourth ventricle. (Figure 2)

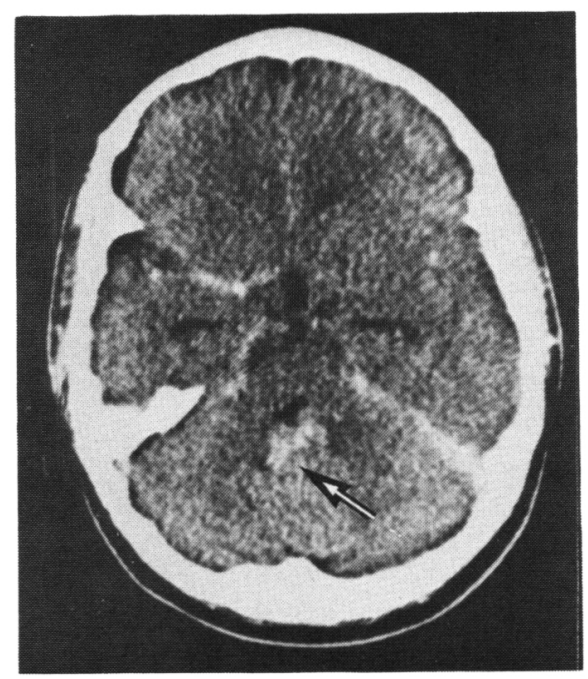

Figure 2 (Case 2) - Enhanced CT scan shows abnormal enhancement of a lesion located within the posterior aspect of the fourth ventricle.

At craniotomy after exposing the cerebellum, a tumor was seen protruding between the cerebellar hemispheres and tonsils. A large tumor was removed from the fourth ventricle which extended to the foramen magnum and up to the aqueduct. It extended out through the foramina of Luschka. Total removal was achieved. The diagnosis was subependymoma of the fourth ventricle.

The patient was last seen nine months after operation and then had a right sixth nerve palsy. There was violent nystagmus on looking to the left, with a rotatory component. She was having trouble adjusting to her disability and required psychiatric help.

\section{CASE 3}

A 35 year old man was seen by an otolaryngologist on October 24th, 1975 with a five month history of episodic vertigo. This was precipitated by turning his head to the left and looking up. It lasted a few seconds and occurred every few days.

On left head hanging, a right beating (ageotropic) horizontal jerk nystagmus was produced. There was no vertigo or latency. The nystagmus was easily reproducible, did not habituate and lasted for five seconds on each of four successive occasions. Audiograms were normal. An ENG showed a low velocity right beatingnystagmus with eyes closed. There was a reduced caloric response on the right. It was thought that he had a right peripheral vestibular abnormality with positional vertigo which was probably benign.

Thirty months later he was seen by a neurologist. Episodic vertigo had become more frequent and severe, occurring several times daily. There was also a history of imbalance for the preceding six or seven months.

On physical examination, right facial myokymia, horizontal bidirectional nystagmus and slight trunkal ataxia were found. A radionuclide brain scan, EEG, and skull $\mathrm{x}$-rays were normal. The CT scan was initially thought to show mild ventricular enlargement, but no evidence of obstruction, and no evidence of tumor. A retrospective assessment is described in Figures $3 \mathrm{~A}, 3 \mathrm{~B}$ and $3 \mathrm{C}$.

Lumbar puncture showed clear cerebrospinal fluid (CSF) under normal pressure, with normal protein, gamma globulin and cell count. Demyelination was considered to be the most likely cause of the illness.

Six months later, the historical and physical features were unchanged.

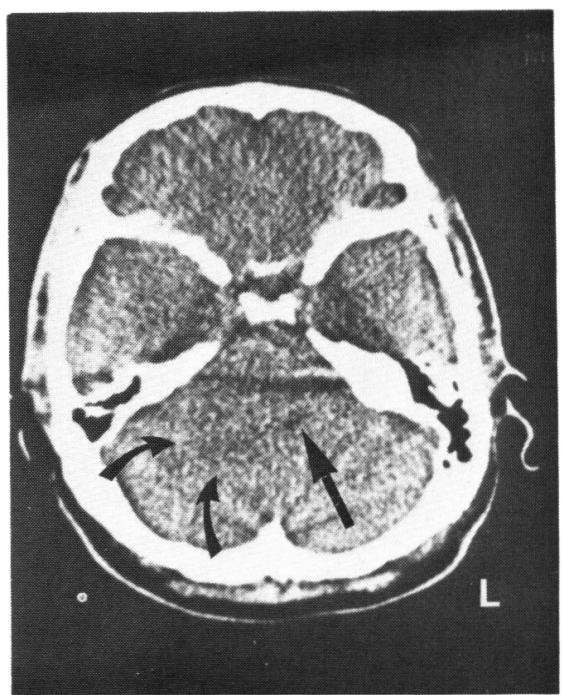

Figure $3 A$ (Case 3) - Non-enhanced $\mathrm{CT}$ scan at the level of the inferior aspect of the posterior fossa shows a poorly defined area of decreased density (curved arrows) in the right cerebellar hemisphere and displacement of the fourth ventricle (straight arrow) to the left. 


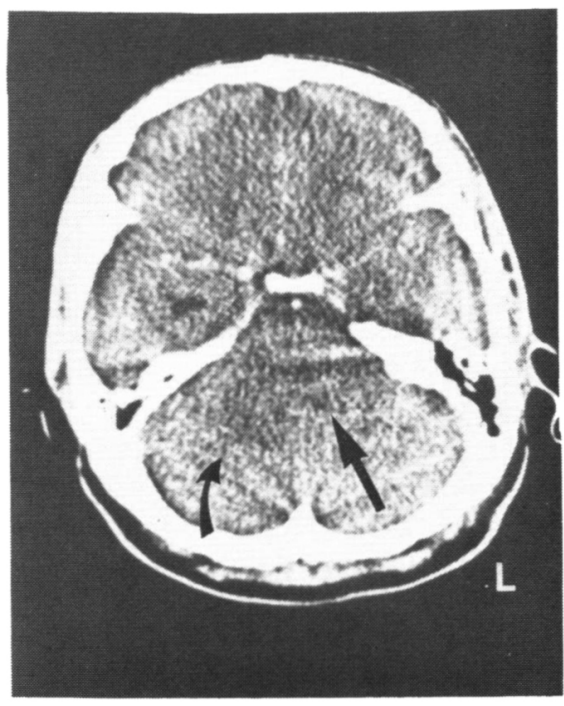

Figure $3 B$ (Case 3) - Enhanced CT scan showed no enhancement of the decreased density lesion (curved arrow) in the right cerebellar hemisphere and displacement of fourth ventricle to the left (straight arrow).

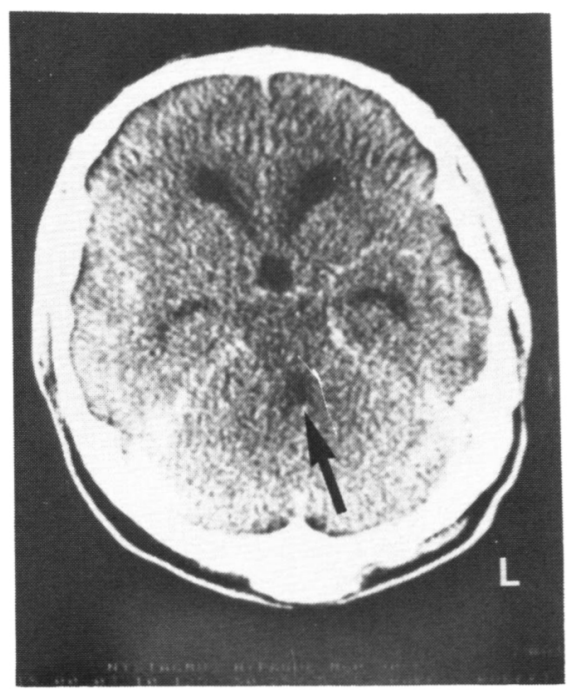

Figure 3 C (Case 3) - Enhanced CT scan at the level of the superior aspect of the posterior fossa showed midline position of the fourth ventricle (arrow) and moderate enlargement of the third and both lateral ventricles.

On September 23, 1978 the patient sought a second neurological opinion; on this occasion the complaints were loss of balance, with headaches which seemed of minor significance. There was nystagmus and an ataxic stiff gait. A lumbar puncture was performed again with normal opening pressure. CSF protein electrophoresis for oligoclonal banding was negative. He was told that he probably had multiple sclerosis.

On October 1, 1978 the patient complained of a severe headache and collapsed. Resuscitation included a ventriculoperitoneal shunt, but the patient died.

At autopsy, an astrocytoma (Figures 7A and $7 \mathrm{~B}$ ) was found to involve the right cerebellar hemisphere and brain stem in the tegmental areas, extended through the upper brain to thalamus, and down to the level of the cervical cord. Compression of the fourth ventricle was prominent. Obstructive hydrocephalus with dilatation of lateral ventricles was no longer present at autopsy, but a shunt was in place. It was thought that he had died of respiratory arrest from medullary compression.

\section{CASE 4}

A 50 year old man presented with severe headaches, vomiting and stupor of 48 hours duration. Four weeks earlier he had a flu-like illness with fever, malaise and myalgia which lasted two or three days. Following this he developed positional vertigo with spells occurring daily, lasting up to 30 seconds, brought on by rolling in bed and getting up or lying down quickly. He was seen by an otolaryngologist who noted transient, geotropic, fatigable, positional nystagmus with vertigo coming on after a latency period of a few seconds with right head hanging. A tentative diagnosis of benign positional vertigo was made. The spells became more frequent and severe, and then headache, nausea and stupor supervened.

Examination revealed a drowsy man who was readily rousable. Papilledema was present with bilateral hyper-reflexia and upgoing toes. A CT scan (Figure 4) showed enlargement of the entire ventricular system. There was no evidence of tumor on CT scan or cerebral angiography. Intracranial pressure monitoring revealed high pressure and plateau waves. A ventriculogram showed obstruction of the fourth ventricle. A ventricupoleritoneal shunt was inserted. The patient recovered; the only apparent cause for the obstruction was elevation of the CSF protein to $180 \mathrm{mgs} \%$. The patient remains well, one year later, with the shunt in place.

\section{DISCUSSION}

Positional nystagmus was first described by Barany $(1910,1921)$. He mentioned two types, one due to peripheral vestibular disorders and the other to lesions of the central nervous system.

Nylen (1939) described probably non-paroxysmal, positional nystag-

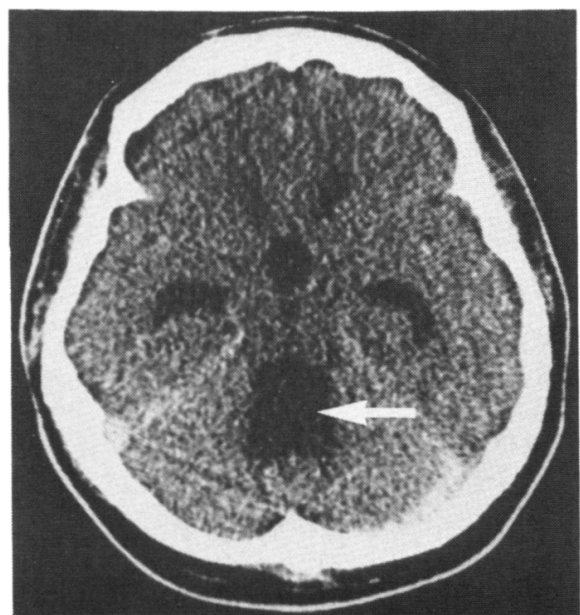

Figure 4A (Case 4) - Enhanced CT scan at the level of the posterior fossa showed marked enlargement of the fourth ventricle (arrow).

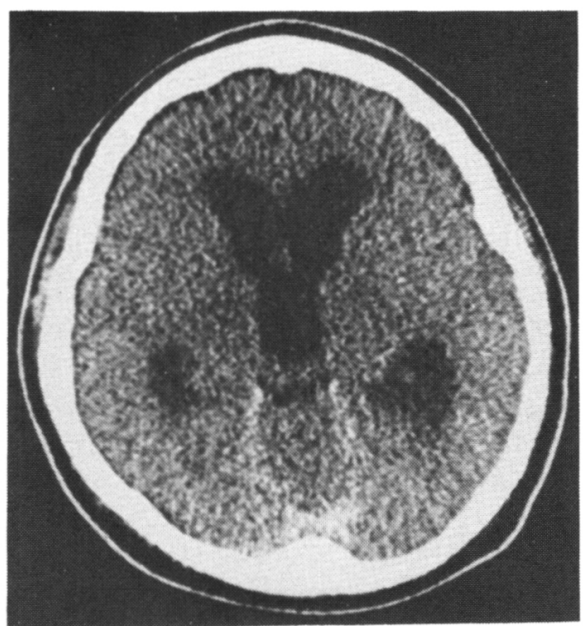

Figure $4 B$ (Case 4) - Enhanced CT scan shows enlargement of the third and both lateral ventricles.

mus in 279 out of 673 cases of brain tumor (230 posterior fossa tumors). The disorder was present in $90 \%$ of posterior fossa tumors and in $26 \%$ of supratentorial neoplasms. He formed two main categories of positional nystagmus; Type I was "direction changing" and Type II "direction fixed". The latter, corresponded somewhat to Barany's first type which Barany described as paroxysmal and due to otolith disorders. Fernandez. and Lindsay (1960) and Aschan (1961) noted an important defect in Nylen's classification, namely, that it did not take into account whether nystagmus 
was persistent or transitory after head positioning. Paroxysmal positional nystagmus has been subsequently described by a number of authors (Dix and Hallpike, 1952; Fernandez and Lindsay, 1960; Aschan, 1961: Barber, 1964).

Dix and Hallpike (1952) introduced the term positional nystagmus of the benign paroxysmal type (PN-BPT), to describe positional nystagmus due to vestibular end-organ disorders. The features of this are as follows. There is usually a latency of several seconds before the appearance of nystagmus. The nystagmus is commonly rotatory with the quick component usually towards the dependent ear. (The eye rotates around an axis extending from cornea to macula, although a varying degree of linear displacement is usually also present). The nystagmus stops spontaneously, usually within 10 seconds. By the third or fourth time the test is repeated, the nystagmus fails to occur and is said to have fatigued. Marked vertigo and consequent distress usually accompanies the nystagmus. Nausea is frequent, vomiting is not. There is usually a single critical position of the head that provokes the nystagmus. The positional nystagmus may be bilateral (Longridge and Barber, 1978), but one-half of patients with this finding have head injury and/or central nervous system disease.

This category of nystagmus constitutes over $85 \%$ of cases of positional nystagmus seen in a vertigo unit. (Barber, 1964) and refers to testing with the eyes open. With the eyes closed PN-BPT is common (Barber and Wright, 1973) and thus must be interpreted with caution. A number of authors have thought that PN-BPT was due to an inner ear abnormality (Barany, 1910, 1921; Dix and Hallpike, 1952; Citron and Hallpike, 1956: Lindsay and Hemenway, 1956; Schuknecht, 1969).

Positional nystagmus has seldom been mentioned as the first and sole presenting feature of brain tumor (Nylen (1939) 5 cases, Riesco MacClure (1957) I case, Gregorius (1976) 2 cases, Drachman (1977) 1 case). When due to central nervous system disease, positional nystagmus usually deviates from the characteristics of PN-BPT as listed above. (Barany, 1910; Nylen,
1939; Fernandez, 1960; Aschan, 1961; Barber, 1964).

There have been three cases of PNBPT described as occurring with brain tumors. Riesco MacClure (1957) described such a case due to an astrocytoma of the inferior cerebellar vermis. Harrison (1972) described a case of posterior fossa malignant glioma with features of PN-BPT but with other symptoms and signs. Case 2 of Drachman (1977) was also thought to have PN-BPT seven months before the diagnosis of a glioblastoma multiforme of the midline cerebellum. It is unclear as to whether any of Nylen's five cases had the exact features of PN-BPT as we know them.

Experimental evidence relating cerebellar lesions and positional nystagmus have been provided by Fernandez et al $(1959,1962)$ and others (Dow, 1938; Spiegel, 1942; Carrea and Metler, 1947; Manni, 1950; Dow and Moruzzi, 1958; Fernandez, 1960). Ablation of the flocculus in cats caused mainly paroxysmal, direction-changing, positional nystagmus in some animals. Ablation of the nodulus and uvula in cats induced positional nystagmus, including that with the features of PB-BPT in humans.

Our cases 2 and 4 illustrate how a posterior fossa tumor and obstructive hydrocephalus may precisely produce PN-PBT. In the former paroxysmal vertigo was the first and sole presenting clinical symptom for some months with no other signs. The youthful age, vomiting (Drachman 1977) and later progressive course were warnings that the positional vertigo and nystagmus were of sinister origin. In Case 2 the mechanism of PN-BPT could have been disinhibition of the vestibular nuclei because of involvement of the nodulus and uvula by tumor. In Case 4 hydrocephalus and raised pressure in the IV ventricle could have impaired nodular inhibitory function or resulted in an hyperexcitable state of the vestibular nuclei as suggested by Riesco Mac-Clure (1957). These cases prove Fernandez (1959) correct in his caution that not every case of PN-BPT is benign and argue for careful followup of all cases of PN-BPT to be certain that it subsides and for further investigation if atypical features are present. These features may include; youthful age and no associated disorder such as head trauma, otitis media, ear surgery, etc., vomiting, other neurological symptoms and signs, and lack of remission and/or progression. The test of most value would appear to be CT head scanning with contrast.

The features of positional nystagmus more likely to be associated with central nervous system disease have been described by a number of authors (Barany 1910, Nylen 1939, Dix 1952, Aschan 1961, Barber 1973, Frederic 1973, Longridge 1978). These features are as follows. There is no latent period before the onset of the nystagmus. The duration of nystagmus is usually greater than 60 seconds. The nystagmus does not fatigue. The nystagmus is more often direction changing (Longridge 1978) than direction fixed, although both types may occur. Marked vertigo is usually not present. The nystagmus may be produced by more than one head position. If classical benign positional vertigo is associated with bilateral paroxysmal positioning nystagmus then head injury and/or central nervous system disease may be found in more than $50 \%$. (Longridge and Barber, 1978). The lesions are mainly infratentorial and include brain stem involvement from such varied causes as acoustic neuroma, Arnold-Chiari malformation, lateral medullary infarction, multiple sclerosis, cerebellar tumor and brain sten concussion from severe head injury.

Our Cases 1 and 3 had features that readily distinguished them from $\mathrm{PN}$ BPT. With Case 1 there was no latency, the nystagmus was linear, did not fatigue and was produced by more than one head position.

The presence of headache aggravated by Valsalva was elicited and not volunteered, but further emphasized the need for further neurological work-up. The positional nystagmus in Case 3 demonstrated a lack of latency, was of an ageotropic, horizontal, jerk nature and did not fatigue. These factors led to follow-up and further investigation which led to the conclusion of central nervous system disease, i.e. multiple sclerosis which was unfortunately erroneous. At autopsy the infiltrating tumor in this case was found to more densely involve the 
flocculonodular lobe of the cerebellum (Figures 5, 6, 7A, 7B).

In conclusion, we have discussed three cases of posterior fossa tumor and a case of obstructive internal hydrocephalus with the first and sole presenting feature of positional vertigo and nystagmus. This symptom may long antedate the appearance of other symptoms and signs of tumor. (Cases 2 and 3). This type of presentation of brain tumor has been referred to infrequently in the past. It is emphasized that the positional nystagmus of posterior fossa tumor and obstructive hydrocephalus may exactly mimic the PN-BPT usually found with benign vestibular end-organ disorders. Followup and CT scanning are necessary to make a diagnosis in these cases.

\section{REFERENCES}

ASCHAN, G. (1961) The Pathogenesis of Positional Nystagmus Acta Otolaryngol. Suppl. 159: 90.

BARANY, R. (1910) quoted in PREBER, L., and SILFERSKIOLD. B.P. Paroxysmal Positional Vertigo Following Head Injury Acta Otolaryngol., 48: 255 (July-Dec) 1957.

BARANY, R. (1921) Diagnose von Krankheitserscheinungen im Bereich des Otolithenapparates. Acta Otolaryngol. 2: 434 (Fasc. 4).

BARBER, H.O. (1973) Positional Vertigo and Nystagmus Otolaryngologic Clinics of North America - Vol. 6. No. I. 169-187.

BARBER, H. (1964) Positional Nystagmus. Especially After Head Injury. Laryngoscope. 74: 891-944.

BARBER, H.O. and WRIGHT, G. (1973) Positional Nystagmus in Normals. Advances Otorhinolaryng. 19.

CARREA, R.M.E. (1946) Physiologic Effects of Bilateral Cerebellar Removals in the Primate. Fed. Proc., 5, 15-16.

CARREA, R.M.E. and METLER, F.A. (1947) Physiologic Consequences Following Extensive Removals of the Cerebellar Cortex and Deep Cerebellar Nuclei and Effect of Secondary Cerebral Ablations in the Primate. I. Comp. Neurol. 87. 169-288.

CITRON, L. and HALLPIKE, C.S. (1956) Observations Upon the Mechanism of Positional Nystagmus of the So-called "Benign Paroxysmal Type" J. Laryng. and Otol. 70: 253-259.

DIX, M.R., HALLPIKE. C.S. (1952) Common Disorders of Vestibular System. Anals Otology. Rhinology and Laryngology. Vol. 61.

DOW, R.S. (1938) Efferent Connections of the Flocculo-Nodular Lobe in Macada Mulatta. J. Comp. Neurol, 68, 297-305.

DOW, R.S. (1938) Effect of Lesions in the Vestibular Part of the Cerebellum in

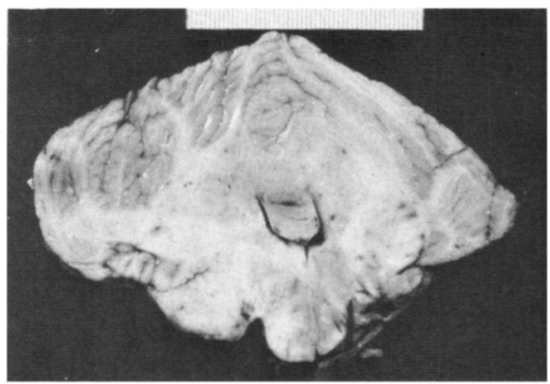

Figure 5 (Case 3) - Transverse section of brain stem at level of upper medulla and cerebellum at level of flocculus and nodulus. Note enlargement of the right cerebellum and brain stem with partial loss of anatomic landmarks.

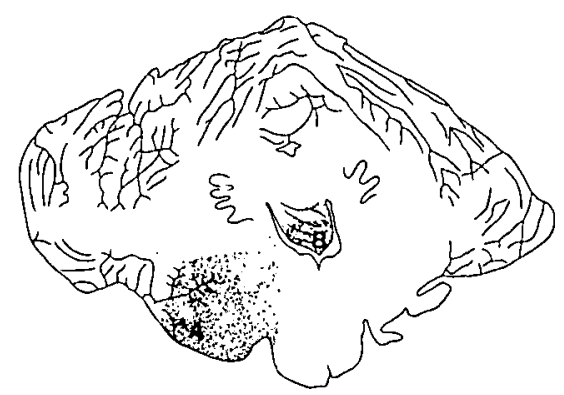

Figure 6 (Case 3) - Line drawing of brain stem and cerebellum seen in Figure 5. Density of stippling represents cellular density of astrocytoma, which is greatest in the areas of the right flocculus (A) and the nodulus (B).

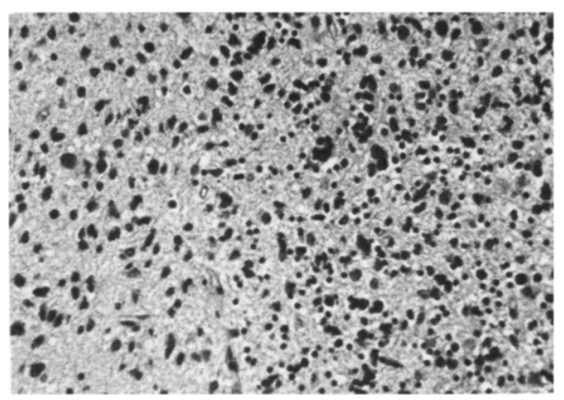

Figure 7A (Case 3) - Astrocytoma in flocculus. The small round nuclei are residual cerebellar granule cells. H \& E obj. x 25 .

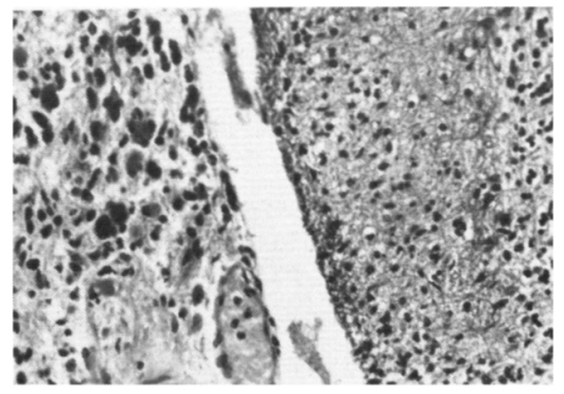

Figure $7 B$ - Astrocytoma in nodulus stained for gliall fibrillary acidic poritein by the indirect unlabelled antibody method. Obj. x 25 .
Primates. Arch. Neurol. and Psychiatr. 40: 500-520.

DOW, R.S. and MORUZZI. G. (1958) The Physiology and Pathology of the CerebelIum. Minneapolis: The University of Minnesota Press.

DRACHMAN, D.A., DIAMOND, E.R., HART, M.D. (1977) Postural-Evoked Vomiting: Associated with Posterior Fossa Lesions Ann. Otol. 86, 97-101.

FERNANDEZ. C. and LINDSAY. J.R. (1960) Positional Nystagmus in Man and Animals. Jour. Nerv. and Ment. Dis. 130: 488 (June).

FERNANDEZ, C. (1960) Interrelations between Flocculonodular lobe and vestibular system. In G.L. Rasmussen and W.F. Windle: Neural. Mechanisms of the Auditory and Vestibular Systems. Springfield: Charles C. Thomas.

FERNANDEZ, C.. ALZATE. R.. LINDSAY. J.R. (1959) Experimental observations on postural nystagmus in the cat. Ann. Otol. Rhinol. Laryngol. 68: 816-829.

FERNANDEZ, C.. FREDERICKSON, J.M. (1962) Experimental Cerebellar Lesions and Their Effect on Vestibular Function. Acta. Otolaryng. Suppl. 192.

FREDERIC. M.W. (1973) Central Vertigo. Otolaryngologic Clinics of North America. Vol. 6. No. I. 267-285

GREGORIUS, F.K., CRANDALI, P.H., BALOH, R.W.. (1976) Positional Vertigo with Cerebellar Astrocytoma. Surgical Neurology, Vol. 6. No. 5. November.

HARRISON, N.S., OZSAHINOGLU, C. (1972) Positional Vertigo: Aetiology and Clinical Significance. Brain 95. 369-372.

LINDSAY, J.R. and HEMENWAY, W.G. (1956) Postural Vertigo Due to Unilateral Sudden Partial Loss of Vestibular Function. Annals of Otology. Rhinology and Laryngology. 65: 692-706.

LONGRIDGE. N.S.. BARBER, H.O. (1978) Bilateral Paroxysmal Positioning Nystagmus. J. of Otolaryngology, Vol. 7, No. 5 . 395-400.

MANNI, E., (1950) Localizzazioni cerebellari corticali nella cavia. Nota 2a: Effeti di lesioni della "parti vestibolari" del cervelletto. Arch. di. Fisiol. 50, 1-14

NYLEN. C.O. (1939) The Oto-neurological Diagnosis of Tumours of the Brain. Helsingfors. Acta Otolaryngo. Suppl. 33.

NYLEN. C.O. (1950) Positional Nystagmus. A Review and Future Prospects. J. Laryng. and Otol. 64 - 295-318.

RIESCO MAC-CLURE. J.S. (1957) Es el vertigo aural de origen exclusivamente periferico? Rev. Otorrinolaring. 17. 42-54.

SCHUKNECHT, H.F. (1962) Positional Vertigo. Clinical and Experimental Observations. Trans Am Acad Ophthal Otolaryngol 66. 319-332.

SCHUKNECHT, H.F. (1969) Cupulolithiasis. Arch. Otolaryngol. 90. 765-778.

SPIEGEL. E.A. and SCALA. N.P. (1942) Positional Nystagmus in Cerebellar Lesions. J. Neurophysiol. 5: 247-260. 